\title{
Oxaliplatin-based versus irinotecan-based hyperthermic intraperitoneal chemotherapy (HIPEC) in patients with peritoneal metastasis from appendiceal and colorectal cancer: a retrospective analysis
}

\author{
Gabriel Glockzin ${ }^{1 *}$, Michael Gerken², Sven A Lang ${ }^{1}$, Monika Klinkhammer-Schalke², Pompiliu Piso ${ }^{1,3}$ \\ and Hans J Schlitt ${ }^{1}$
}

\begin{abstract}
Background: Cytoreductive surgery (CRS) and hyperthermic intraperitoneal chemotherapy (HIPEC) provide an effective treatment option for selected patients with colorectal peritoneal metastasis with encouraging survival results. Many different drug combinations and HIPEC regimens including bidirectional, i.e. synchronous intravenous and intraperitoneal, drug application have been used. However, there is still no standardization of the HIPEC regimen.

Methods: Between 05/2007 and 04/2010 190 patients underwent CRS and HIPEC at the University Hospital Regensburg. Thirty-two patients with peritoneal metastasis arising from colorectal or appendiceal cancer underwent complete macroscopic cytoreduction (CC-0/1) and bidirectional HIPEC and completed at least 3-year follow-up. Twenty patients received oxaliplatin-based (OX) and twelve patients received irinotecan-based HIPEC (IRI). Group-specific perioperative morbidity and 3-year survival has been determined.
\end{abstract}

Results: The grade $3 / 4$ morbidity rate according to CTCAE v4 was $35.0 \%$ in the OX group vs. $33.3 \%$ in the IRI group ( $p=1.000$ ). There was no perioperative mortality in both groups. Median survival was 26.8 months (95\% Cl 15.7-33.1 months) in the IRI group and has not yet been reached in the OX group during a median follow-up of 39.4 months. Three-year survival rates were $65.0 \%$ in the OX group vs. $41.7 \%$ in the IRI group ( $p=0.295$ ).

Conclusions: The morbidity and toxicity rates of bidirectional irinotecan-based and oxaliplatin-based HIPEC are comparable. Nevertheless, in the absence of contraindications oxaliplatin-based HIPEC might be preferred due to the positive trend regarding 3-year and median survival.

Keywords: Peritoneal carcinomatosis, HIPEC, Irinotecan, Oxaliplatin, Morbidity, Survival

\section{Background}

The combined treatment concept consisting of cytoreductive surgery (CRS) and hyperthermic intraperitoneal chemotherapy (HIPEC) performed in specialized centers has shown to be a safe and efficient additive therapeutic option for selected patients with colorectal peritoneal metastasis [1-3]. One prospective randomized controlled

\footnotetext{
*Correspondence: gabriel.glockzin@ukr.de

'Department of Surgery, University Hospital Regensburg, 93042 Regensburg, Germany

Full list of author information is available at the end of the article
}

phase III trial and several prospective and retrospective reports provide evidence for improved long-term survival for CRS and HIPEC as an integrative part of an interdisciplinary treatment regimen [4-9]. In the Dutch RCT the median survival of patients who underwent CRS and HIPEC was 22 months vs. 12.6 months in the control group with systemic chemotherapy only. In the subgroup analysis of patients after complete macroscopic cytoreduction (CC-0/1) median survival increased to 42.9 months $[8,9]$. As in most other reported studies and series a mitomycin C (MMC)-based HIPEC regimen has been used for 
peritoneal perfusion. Based on the results of modern systemic polychemotherapy regimens such as FOLFOX or FOLFIRI for patients with metastatic colorectal cancer oxaliplatin and irinotecan have also been used for peritoneal perfusion. Data first published from the French groups suggest that oxaliplatin-based HIPEC after complete macroscopic cytoreduction may further improve survival of patients with colorectal peritoneal metastasis [10,11]. The addition of intraperitoneal irinotecan to the bidirectional oxaliplatin-based HIPEC regimen did not lead to improved overall or relapse-free survival [12]. Nevertheless, as irinotecan is considered to be the second most effective agent for the treatment of patients with colorectal cancer [13,14], bidirectional irinotecan-based HIPEC might be a promising alternative treatment regimen for patients with disease progression or intolerable adverse events under oxaliplatin-based chemotherapy as well as patients with good response under previous systemic chemotherapy with irinotecan. However, conclusive data from randomized controlled trials is still missing and numerous different HIPEC regimens are used for treatment of colorectal peritoneal metastasis [15]. Cytostatic agents, drug dosage and duration of perfusion are still a matter of debate.

In the present study we retrospectively analyzed morbidity, mortality and 3-year survival of thirty-two patients with peritoneal metastasis arising from colorectal or appendiceal cancer who received either bidirectional oxaliplatin-based or irinotecan-based HIPEC after complete macroscopic cytoreduction.

\section{Methods}

Between May 2007 and April 2010190 patients underwent cytoreductive surgery (CRS) and hyperthermic intraperitoneal chemotherapy (HIPEC) for various peritoneal surface malignancies at the University Hospital Regensburg. Thirty-two patients with synchronous or metachronous peritoneal metastasis arising from colorectal or appendiceal cancer received bidirectional HIPEC after complete macroscopic cytoreduction (CC-0/1). Twenty patients received oxaliplatin-based HIPEC and twelve patients received irinotecan-based HIPEC. All patients had histologically proven peritoneal carcinomatosis arising from colorectal or appendiceal adenocarcinoma. Patients with disseminated peritoneal adenomucinosis (DPAM) or peritoneal mucinous carcinomatosis of intermediate features (PMCA-I) as well as patients with incomplete macroscopic cytoreduction (CC-2 or CC-3) were excluded from the present study.

Data has been analyzed retrospectively. The retrospective analysis from a database without the use of patients' personal data was exempted from approval by the Ethics Committee at the Regensburg University. Nevertheless, CRS and HIPEC are recommended for selected patients by the German S3-guideline for the treatment of colorectal cancer [16]. Moreover, the bidirectional oxaliplatinbased HIPEC regimen has been approved by the ethic committee in the context of our prospective multicenter phase II COMBATAC trial (ClinicalTrials.gov Identifier: NCT01540344) [17] and is recommended as one of the standard HIPEC protocols for patients with colorectal peritoneal metastasis by the German Peritoneal Surface Malignancy Group. The individual reasons for the replacement of oxaliplatin by irinotecan in the IRI group are summarized in Table 1 . The safety of intraperitoneal application of irinotecan has been proven in several published studies $[12,18,19]$. However, due to the lack of consistent data there are still no national and/or international standards for HIPEC regimens in patients with colorectal peritoneal metastasis [15].

All patients included in the present retrospective study at least completed a 3-year follow-up period. The median follow-up time including events of death was 37.8 months (range 7-51).

Morbidity and toxicity were classified using the Common Terminology Criteria for Adverse Events version 4.0 (CTCAE v4.02) of the U.S. National Cancer Institute. Perioperative mortality was defined as death within 30 days after surgery or in-hospital mortality in case of hospital stay longer than 30 days.

\section{Cytoreductive surgery}

Cytoreductive surgery consists of numerous surgical and peritonectomy procedures depending on the extent of peritoneal tumor dissemination that was determined by the intraoperative calculation of the Peritoneal Cancer Index (PCI) [20,21]. Operating procedures were performed as described previously [22,23]. After complete macroscopic cytoreduction (CC-0/1) one inflow drainage, three outflow drainages and two temperature probes were placed in the abdomen to allow the application of HIPEC.

\section{Hyperthermic intraperitoneal chemotherapy}

In all patients bidirectional HIPEC with additional intravenous application of 5 -FU at a concentration of $400 \mathrm{mg} /$ sqm body surface and folinic acid at a concentration of $20 \mathrm{mg} / \mathrm{sqm}$ body surface about 30 minutes prior to peritoneal chemoperfusion was performed in closed abdomen technique. Abdominal perfusion was started with a total volume of 31 sodium chloride $0.9 \%$ over the inflow drainage using a roller pump system with heat exchanger (ThermaSolutions Inc., Netherlands). Cytostatic agents were added after the temperature in Douglas pouch reached at least $40^{\circ} \mathrm{C}$ and perfusion was continued for 30 minutes keeping an intraperitoneal temperature of $41-43^{\circ} \mathrm{C}$. In the OX group the abdominal cavity was perfused with oxaliplatin at a concentration of $300 \mathrm{mg} / \mathrm{sqm}$ 
Table 1 Characteristics of patients with irinotecan-based HIPEC

\begin{tabular}{lllll}
\hline Patient & Previous syst. CTx & Previous syst. OX & Recurrent PM & Rationale for irinotecan-based HIPEC \\
\hline Patient 1 & yes & yes & yes & Oxaliplatin-associated peripheral neuropathy \\
Patient 2 & yes & yes & no & $2^{\text {nd line irinotecan-based systemic chemothera-py after disease progression }}$ \\
Patient 3 & yes & no & no & Systemic irinotecan-based chemotherapy with response \\
Patient 4 & yes & yes & no & Systemic irinotecan-based chemotherapy with response \\
Patient 5 & yes & no & no & Systemic irinotecan-based chemotherapy with response \\
Patient 6 & yes & no & no & Systemic irinotecan-based chemotherapy with response \\
Patient 7 & yes & no & no & Oxaliplatin-associated peripheral neuropathy \\
Patient 8 & yes & yes & no & Systemic irinotecan-based chemotherapy with response \\
Patient 9 & yes & no & no & Progressive disease under oxaliplatin-based systemic chemotherapy \\
Patient 10 & yes & yes & yes & Progressive disease under oxaliplatin-based systemic chemotherapy \\
Patient 11 & yes & yes & no & Systemic irinotecan-based chemotherapy with response \\
Patient 12 & yes & no &
\end{tabular}

$\mathrm{CTx}=$ chemotherapy; $\mathrm{PM}=$ peritoneal metastasis.

body surface and in the IRI group with $300 \mathrm{mg} / \mathrm{sqm}$ body surface irinotecan for 30 minutes, respectively.

\section{Statistics}

Kaplan-Maier survival analysis was performed. P-values were calculated using T-test, Chi square and Log rank test as applicable. A two-sided p-value $<0.05$ was defined to be statistically significant. Statistical analysis was performed using IBM SPSS Statistics for Windows version 19 (SPSS Inc., IBM Corporation, USA).

\section{Results}

\section{Patients' characteristics}

The mean age of patients was 54 years (range 20-68) with 53 years (range 20-68) in the OX group and 54 years (range 42-66) in the IRI group. Fourteen patients were female and eighteen male. The distribution of American Society of Anaesthesiologists (ASA) scores was $9.4 \%$ for ASA I, $71.9 \%$ for ASA II and $18.8 \%$ for ASA III, respectively.

Patient and tumor characteristics including localization of the primary tumor are summarized in Table 2. The OX group includes a higher number of patients with peritoneal metastasis from appendiceal adenocarcinoma $(\mathrm{p}=$ 0.139 ) and a lower number with primary colon carcinoma $(p=0.073)$ compared to the IRI group. Nevertheless, the differences were not statistically significant. Moreover, there was a not significant higher number of lymph node negative primary tumors $(\mathrm{p}=0.066)$ and well differentiated adenocarcinomas $(\mathrm{G} 1, \mathrm{p}=0.130)$ in the $\mathrm{OX}$ group. In one patient in the IRI group the $\mathrm{T}$ and $\mathrm{N}$ status of the primary tumor was not documented.

The mean PCI was 13 (range 2-18). 50\% of the patients had synchronous and $31.3 \%$ metachronous peritoneal metastasis. Six patients showed recurrent disease (18.8\%) and four patients had liver metastases at the time of surgery
(12.5\%). Fourteen patients had previous abdominal surgery $(43.8 \%)$ and 24 patients $(75.0 \%)$ already underwent oncologic abdominal surgery for primary tumor or metastasis. Five patients had previous CRS and HIPEC (15.6\%). There were no significant differences between the two groups.

Most patients (87.5\%) already received systemic chemotherapy during the course of their disease consisting of different chemotherapy regimens. More than half of the patients $(53.1 \%)$ had previous oxaliplatin-based systemic chemotherapy.

\section{Operative and perioperative data}

Operative and perioperative data is summarized in Table 3. The mean operating time was 348 minutes (range 149586) with 337 minutes (range 149-586) in the OX group and 366 minutes (range 200-557) in the IRI group, respectively $(\mathrm{p}=0.497)$. The mean blood loss was $271 \mathrm{ml}$ (range 100-600), and the mean number of anastomoses was 1.19 (range 0-3). There were no significant differences between the two groups.

The detailed surgical and peritonectomy procedures are summarized in Table 4 . There were no statistically significant differences regarding surgery between the two groups.

The median hospital stay was 15 days (range 9-38) in the OX group and 15.5 days (range 8-42) in the IRI group, respectively $(p=0.863)$. The median stay on ICU was one day (range $0-6)$ in both groups $(\mathrm{p}=0.332)$.

\section{Morbidity and mortality}

The overall grade $3 / 4$ morbidity rate according to CTCAE v4.02 was $34.4 \%$ with $35.0 \%$ in the OX group and $33.3 \%$ in the IRI group, respectively $(\mathrm{p}=1.000)$. Postoperative complications are summarized in detail in Table 5. In the OX group two patients developed pleural effusion requiring 
Table 2 Patient and tumor characteristics

\begin{tabular}{lllll}
\hline & Overall & OX & IRI & $p$-value \\
Number of patients [n] & 32 & 20 & 12 & \\
\hline
\end{tabular}

I. Patient characteristics

Mean age (range) [y] $54(20-68) \quad 53(20-68) \quad 54(42-66) \quad 0.842$

Sex [n] - male

- female

$14(43.8 \%) \quad 9(45.0 \%) \quad 5(41.7 \%)$

$18(56.3 \%) \quad 11(55.0 \%) \quad 7(52.8 \%) \quad 1.000$

ASA score [n]

- ASA I

- ASA II

- ASA III

$\begin{array}{llll}3(9.4 \%) & 2(10.0 \%) & 1(8.3 \%) & 1.000 \\ 23(71.9 \%) & 14(70.0 \%) & 9(75.0 \%) & 1.000 \\ 6(18.8 \%) & 4(20.0 \%) & 2(16.7 \%) & 1.000\end{array}$

II. Localization of primary tumor

$\begin{array}{lllll}\text { Appendix } & 11(34.4 \%) & 9(45.0 \%) & 2(16.7 \%) & 0.139 \\ \text { Colon } & 7(21.9 \%) & 2(10.0 \%) & 5(41.7 \%) & 0.073 \\ \text { Sigma } & 10(31.3 \%) & 7(35.0 \%) & 3(25.0 \%) & 0.702 \\ \text { Rectum } & 4(12.5 \%) & 2(10.0 \%) & 2(16.7 \%) & 0.620 \\ \text { III. Initial TNM classification } & & & & \\ \text { T2 } & 1^{*}(3.2 \%) & 1(5.0 \%) & 0^{* *} & 1.000 \\ \text { T3 } & 10^{*}(32.3 \%) & 6(30.0 \%) & 4^{* *}(36.4 \%) & 1.000 \\ \text { T4 } & 20^{*}(64.5 \%) & 13(65.0 \%) & 7^{* *}(63.7 \%) & 1.000 \\ \text { N0 } & 16^{*}(51.6 \%) & 13(65.0 \%) & 3^{* *}(27.3 \%) & 0.066 \\ \text { N1 } & 5^{*}(16.1 \%) & 2(10.0 \%) & 3^{* *}(27.3 \%) & 0.317 \\ \text { N2 } & 10^{*}(32.3 \%) & 5(25.0 \%) & 5^{* *}(45.5 \%) & 0.423 \\ \text { M1 } & 22(68.8 \%) & 14(70.0 \%) & 8(66.7 \%) & 1.000 \\ \text { G1 } & 5(15.6 \%) & 5(25.0 \%) & 0 & 0.130 \\ \text { G2 } & 11(34.4 \%) & 7(35.0 \%) & 4(33.3 \%) & 1.000 \\ \text { G3 } & 16(50.0 \%) & 8(40.0 \%) & 8(66.7 \%) & 0.273\end{array}$

IV. Further tumor characteristics

\begin{tabular}{|c|c|c|c|c|}
\hline Mean $\mathrm{PCl}$ (range) & $13(2-28)$ & $13(4-28)$ & $12(2-28)$ & 0.630 \\
\hline Synchronous PM & $16(50.0 \%)$ & $10(50.0 \%)$ & $6(50.0 \%)$ & 1.000 \\
\hline Metachronous PM & $10(31.3 \%)$ & $6(30.0 \%)$ & $4(33.3 \%)$ & 1.000 \\
\hline Recurrent disease & $6(18.8 \%)$ & $4(20.0 \%)$ & $2(16.7 \%)$ & 1.000 \\
\hline Liver metastasis & $4(12.5 \%)$ & $1(5.0 \%)$ & $3(25.0 \%)$ & 0.271 \\
\hline \multicolumn{5}{|l|}{ V. Medical history } \\
\hline $\begin{array}{l}\text { Previous abdominal } \\
\text { surgery }\end{array}$ & $14(43.8 \%)$ & $9(45.0 \%)$ & $5(41.7 \%)$ & 1.000 \\
\hline $\begin{array}{l}\text { Previous oncologic } \\
\text { surgery }\end{array}$ & $24(75.0 \%)$ & $14(70.0 \%)$ & $10(83.3 \%)$ & 0.676 \\
\hline $\begin{array}{l}\text { Previous CRS and } \\
\text { HIPEC }\end{array}$ & $5(15.6 \%)$ & $3(15.0 \%)$ & $2(16.7 \%)$ & 1.000 \\
\hline Previous chemotherapy & $28(87.5 \%)$ & $16(80.0 \%)$ & $12(100 \%)$ & 0.271 \\
\hline $\begin{array}{l}\text { Previous systemic } \\
\text { oxaliplatin }\end{array}$ & $17(53.1 \%)$ & $11(55.0 \%)$ & $6(50 \%)$ & 1.000 \\
\hline
\end{tabular}

${ }^{*} \mathrm{n}=31,{ }^{* *} \mathrm{n}=11$.

intervention. Moreover, ileus, intraabdominal abscess, bowel perforation, lung embolism, and cardiac arrhythmia were observed. In the IRI group ileus, postoperative bleeding, wound infection and pneumonia occurred. There was
Table 3 Operative and perioperative data

\begin{tabular}{|c|c|c|c|c|}
\hline & Overall & OX & IRI & $p$-value \\
\hline Number of patients [n] & 32 & 20 & 12 & \\
\hline \multicolumn{5}{|l|}{ I. Operative data } \\
\hline $\begin{array}{l}\text { Mean operating } \\
\text { time [min] }\end{array}$ & $348(149-586)$ & 337 & 366 & 0.497 \\
\hline $\begin{array}{l}\text { Mean blood } \\
\text { loss [ml] }\end{array}$ & $271(100-600)$ & 257 & 280 & 0.760 \\
\hline $\begin{array}{l}\text { Mean no. of } \\
\text { anastomoses }\end{array}$ & 1.19 & 1.21 & 1.17 & 0.899 \\
\hline \multicolumn{5}{|l|}{ II. Perioperative data } \\
\hline $\begin{array}{l}\text { Median stay on } \\
\text { ICU [d] }\end{array}$ & $1(0-6)$ & $1(0-5)$ & $1.5(0-6)$ & 0.332 \\
\hline $\begin{array}{l}\text { Median hospital } \\
\text { stay [d] }\end{array}$ & $15.5(9-42)$ & $15(9-38)$ & $15.5(8-42)$ & 0.863 \\
\hline Morbidity ${ }^{\circ} 3 / 4[n]$ & $11(34.4 \%)$ & $7(35.0 \%)$ & $4(33.3 \%)$ & 1.000 \\
\hline $\begin{array}{l}\text { In-hospital } \\
\text { mortality [n] }\end{array}$ & 0 & 0 & 0 & 1.000 \\
\hline 30-day mortality [n] & 0 & 0 & 0 & 1.000 \\
\hline Revision surgery [n] & $3(9.4 \%)$ & $1(5.0 \%)$ & $2(16.7 \%)$ & 0.540 \\
\hline
\end{tabular}

no documented hematological toxicity requiring intervention in both groups. Three patients (9.4\%), one patient in the OX group (5.0\%) and two patients in the IRI group (16.7\%), required revision surgery due to postoperative complications $(\mathrm{p}=0.540)$. Reasons for re-operation were postoperative bleeding, small bowel perforation and extensive wound infection.

Perioperative morbidity defined as 30-day or in-hospital mortality (depending on the length of hospital stay) was $0 \%$ in both groups.

\section{Survival analysis}

The overall 2-year and 3-year survival rates were $68.8 \%$ and $56.3 \%$, respectively (Figure $1 \mathrm{~A}$ ). The group-specific 2 -year survival rates were $70.0 \%$ in the OX group and $66.7 \%$ in the IRI group $(\mathrm{p}=0.846)$. The 3 -year survival rates reached $65.0 \%$ in the OX group and $41.7 \%$ in the IRI group $(p=0.295)$. This difference was not statistically significant (Figure 1B). In the OX group median survival has not yet been reached during follow-up. The median follow-up time including events of death in this group of patients was 39.4 months (range 7.2-51.1). The IRI group showed a median survival of 26.8 months (95\% CI 15.7-33.1 months).

Subgroup analysis showed a 3-year overall survival rate of $72.7 \%$ in 11 patients with appendiceal primary compared to $47.6 \%$ in 21 patients with peritoneal metastasis arising from colonic, sigmoid or rectal cancer (Figure 2, $\mathrm{p}=0.213$ ). After three years $68.8 \%$ of patients with negative initial lymph node status survived $(\mathrm{n}=16)$ compared to $46.7 \%$ of patients with positive lymph nodes $(\mathrm{n}=15)$ at time of first diagnosis $(\mathrm{p}=0.231)$. There was also no 
Table 4 Peritonectomy and surgical procedures

\begin{tabular}{lllll}
\hline Number of patients [n] & Overall & OX & IRI & p-value \\
\hline Greater omentectomy & $\mathbf{3 2}$ & $\mathbf{2 0}$ & $\mathbf{1 2}$ & \\
Upper right peritonectomy & 24 & 17 & 7 & 0.204 \\
Upper left peritonectomy & 21 & 14 & 7 & 0.703 \\
Parietal peritonectomy & 7 & 5 & 2 & 0.683 \\
Pelvic peritonectomy & 9 & 6 & 3 & 1.000 \\
Small bowel resection & 22 & 15 & 7 & 0.438 \\
Colonic resection & 19 & 12 & 7 & 1.000 \\
Rectal resection & 17 & 11 & 6 & 1.000 \\
Cholecystectomy & 20 & 13 & 7 & 0.999 \\
Liver resection & 9 & 6 & 3 & 1.000 \\
Gastric resection & 5 & 1 & 4 & 0.053 \\
Splenectomy & 3 & 1 & 2 & 0.540 \\
Ovarectomy & 6 & 3 & 3 & 0.647 \\
Hysterectomy & 2 & 0 & 2 & 0.133 \\
Vesical resection & 3 & 1 & 2 & 0.540 \\
Loop ileostomy & 2 & 1 & 1 & 1.000 \\
Overall number of peritonectomy & 83 & 57 & 26 & 0.104 \\
procedures & 4 & 3 & 1 & 1.000 \\
Overall number of visceral resections & 86 & 49 & 37 & 0.142 \\
\hline
\end{tabular}

statistically significant difference regarding 3-year survival rates depending on the histological grading. Overall 3-year survival rates were $60.0 \%$ for patients with well differentiated primary tumors $(\mathrm{G} 1, \mathrm{n}=5), 54.5 \%$ for patients with moderately differentiated primary tumors $(\mathrm{G} 2, \mathrm{n}=11)$ and $53.6 \%$ for patients with poorly differentiated primary tumors ( $\mathrm{G} 3, \mathrm{n}=16)$, respectively $(\mathrm{p}=0.998)$.

\section{Discussion}

The multimodality treatment concept of cytoreductive surgery (CRS) and hyperthermic intraperitoneal chemotherapy (HIPEC) is associated with significant rates perioperative morbidity. Beyond patient factors such as

Table 5 Postoperative complications grade 3/4

\begin{tabular}{lllll}
\hline Number of patients [n] & Overall & $\mathbf{0 X}$ & $\mathbf{I R I}$ & $\boldsymbol{p}$-value \\
\hline Pleural effusion & $2(6.3 \%)$ & $2(10.0 \%)$ & 0 & 0.516 \\
Pneumonia & $1(3.1 \%)$ & 0 & $1(8.3 \%)$ & 0.375 \\
Lung embolism & $1(3.1 \%)$ & $1(5.0 \%)$ & 0 & 1.000 \\
Bowel perforation & $1(3.1 \%)$ & $1(5.0 \%)$ & 0 & 1.000 \\
lleus & $2(6.3 \%)$ & $1(5.0 \%)$ & $1(8.3 \%)$ & 1.000 \\
Postoperative bleeding & $1(3.1 \%)$ & 0 & $1(8.3 \%)$ & 0.375 \\
Wound infection & $1(3.1 \%)$ & 0 & $1(8.3 \%)$ & 0.375 \\
Intraabdominal abscess & $1(3.1 \%)$ & $1(5.0 \%)$ & 0 & 1.000 \\
Cardiac arrhythmia & $1(3.1 \%)$ & $1(5.0 \%)$ & 0 & 1.000 \\
\hline
\end{tabular}

comorbidities the operative risk of CRS depends on the extent of surgery and the distinctive features of the performed surgical procedures. HIPEC may cause additional chemotherapy-related complications and toxicity. In the literature morbidity rates in specialized peritoneal carcinomatosis centers range from $23 \%$ to $45 \%$ depending on the assessment and definition of perioperative complications [3,4,7,24-27]. Quenet et al. reported an in increase of the morbidity rate from $34.9 \%$ to $52.4 \%$ by adding intraperitoneal irinotecan to an oxaliplatin-based bidirectional HIPEC regimen [12]. In the present study the overall grade $3 / 4$ morbidity rate was $34.4 \%$. Although pharmacokinetic studies on heated intraperitoneal oxaliplatin reported dose absorption rates from $40 \%$ to $68 \%$ within 30 minutes perfusion [28,29], we found no hematologic toxicity requiring intervention neither in the $\mathrm{OX}$ nor in the IRI group. This result is consistent with previous observations [30,31]. Nevertheless, Elias et al. reported a haematological toxicity rate of $11 \%$ after bidirectional HIPEC with intraperitoneal oxaliplatin plus irinotecan [18]. In a systematic review including numerous different HIPEC regimens the mean overall rate of hematologic toxicity was $5.6 \%$ [32]. The low chemotherapy-related morbidity in our series may be caused by the concentration of $300 \mathrm{mg} / \mathrm{sqm}$ body surface in comparison to $460 \mathrm{mg} / \mathrm{sqm}$ body surface in the French series. In a recently published study of oxaliplatin pharmacokinetics during bidirectional HIPEC the oxaliplatin dose has been reduced from $460 \mathrm{mg} / \mathrm{sqm}$ body surface to $360 \mathrm{mg} / \mathrm{sqm}$ body surface after the first 17 patients due to toxicity [33].

In the present series three patients had to be reoperated for perioperative complications (9.4\%). In the literature revision surgery is reported for $8.2 \%$ to $14 \%$ of patients that underwent CRS and HIPEC [3,25,26,34]. The recently published data from the American College of Surgeons National Surgical Quality Improvement Program showed a re-operation rate of $10 \%$ [35]. There was no perioperative mortality in the present study. In a systematic review of 155 articles published by Chua et al. the mean mortality rate was $2.9 \%$ ranging from $0 \%$ to 17\% [32]. In the American College of Surgeons National Surgical Quality Improvement Program hospitals overall morbidity rate was $2 \%$ [35]. Hospital stay and stay on ICU did not differ between the two groups in our series and were comparable to published data $[3,7,9,24,30,34,35]$.

The safety and efficacy of intravenous oxaliplatin and irinotecan in combination with 5-FU and folinic acid has been demonstrated in numerous studies [36-43]. Both cytostatic agents are considered to be part of the standard treatment of advanced colorectal cancer. Nevertheless, systemic treatment is less efficient in patients with peritoneal metastasis [44]. Franko et al. compared the outcome of 2,095 patients enrolled onto two prospective randomized clinical trials evaluating systemic chemotherapy 


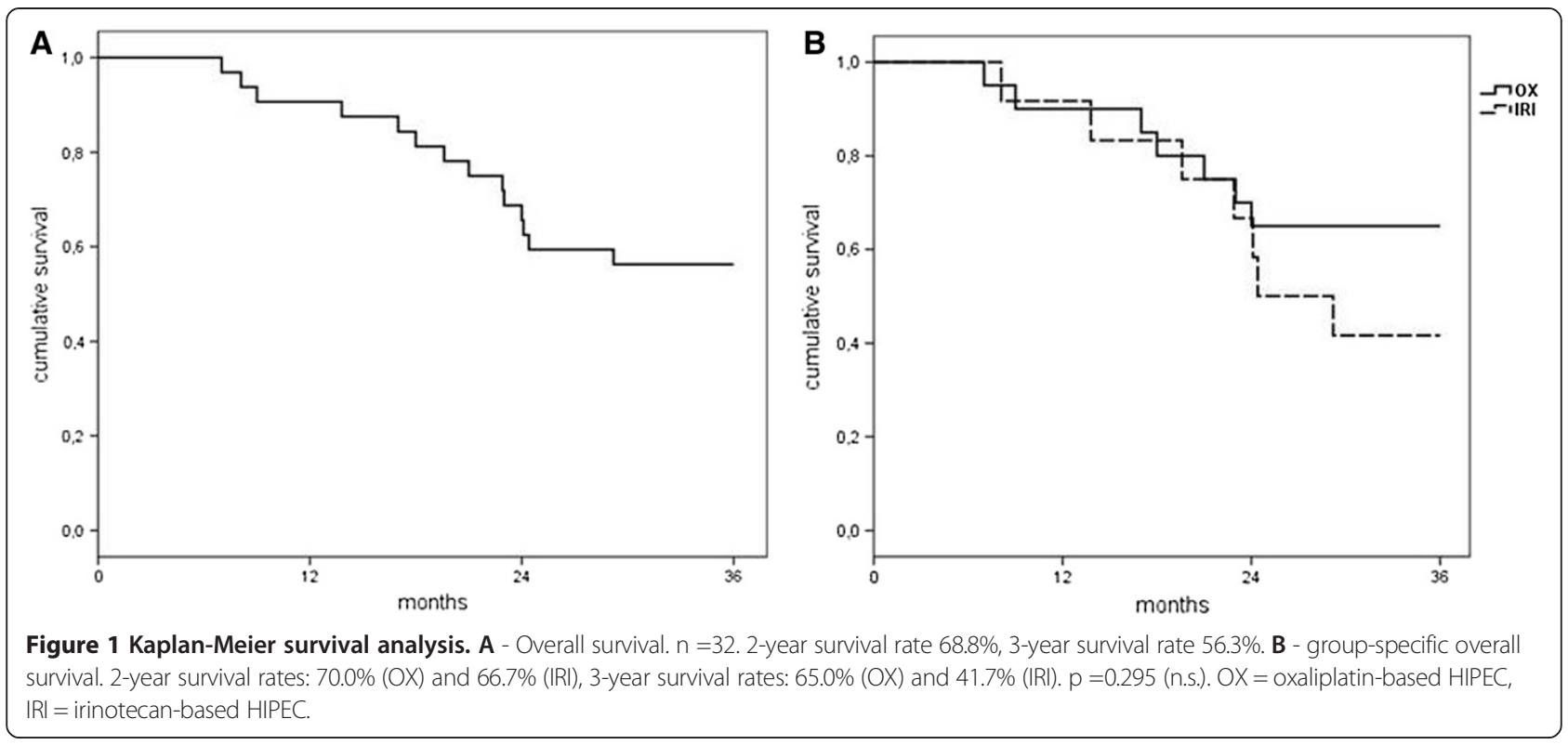

for patients with $\mathrm{CRC}$ with (pcCRC) and without peritoneal metastasis (non-pcCRC) and reported median survival of 12.7 months in the pcCRC group $(\mathrm{n}=364)$ vs. 17.6 months in the non-pcCRC group. In this analysis infusional oxaliplatin-based chemotherapy was superior to irinotecan in first line therapy of pcCRC patients [14].
Based on the successful use of systemic oxaliplatin, 5fluorouracil and folinic acid in patients with mCRC bidirectional HIPEC with intraperitoneal oxaliplatin and intravenous 5 -FU/folinic acid has been used within the multimodality concept of CRS and HIPEC in patients with peritoneal metastasis arising from CRC. Elias et al.

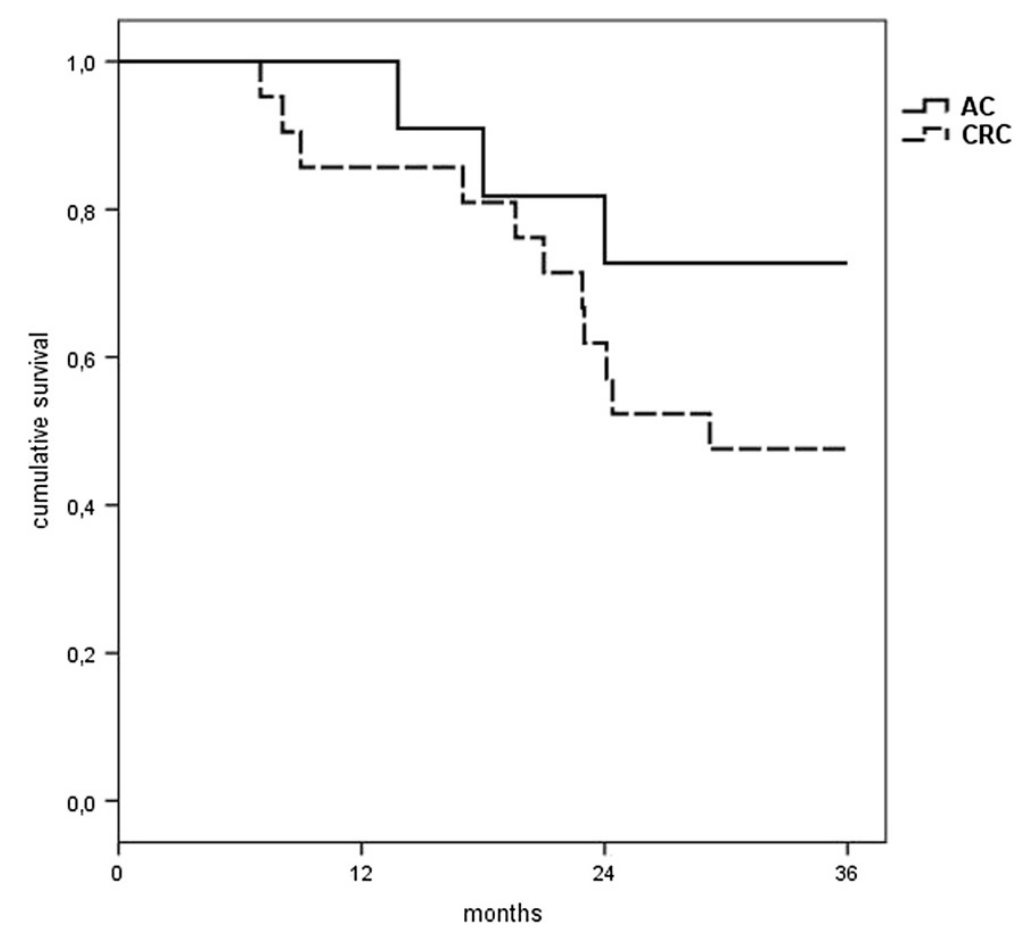

Figure 2 3-year survival depending on primary tumor. Overall survival of patients with appendiceal cancer $(n=11)$ vs. patients with colorectal cancer $(n=21)$ as primary tumor. 3-year survival rates: $72.7 \%(A C)$ and $47.6 \%(C R C) . p=0.213$ (n.s.). AC = appendiceal cancer, $C R C=$ colorectal cancer. 
reported promising results with a median survival of 62.7 months and a 5 -year survival rate of 51\% [11]. In a prospective phase II study published by Hompes et al. the 2-year overall survival rate reached $88.7 \%$ and the median disease-free survival (DFS) was 19.8 months [45]. Consistent with this data the 3-year survival rate in our series was $65.0 \%$. In contrast to the results for systemic treatment using the FOLFOXIRI protocol published by Falcone et al. [38] addition of intraperitoneal irinotecan to the bidirectional oxaliplatin-based HIPEC regimen did not lead to improved overall or relapse-free survival. Quenet et al. reported a median overall survival 47 months and a 5-year survival rate of $42.4 \%$ [12]. The survival data of a phase I trial combining irinotecan with mitomycin C for HIPEC is not yet available [19].

In the present retrospective analysis the rationale for intraperitoneal irinotecan was response to systemic irinotecan-based chemotherapy in seven patients, disease progression under oxaliplatin-based systemic chemotherapy in three and oxaliplatin-associated peripheral polyneuropathy $\geq$ grade 3 in two patients. Median overall survival was 26.8 months and 3 -year survival rate $41.7 \%$ in the IRI group suggesting a negative trend compared to the OX group as well as most published survival data after complete macroscopic cytoreduction and HIPEC with other cytostatic agents or combinations $[8,9,11,45]$. Nevertheless, in a recently published retrospective analysis of 95 patients Hompes et al. reported a median overall survival of 37.1 months after oxaliplatin-based HIPEC and 26.5 months for the mitomycin C-based HIPEC after complete macroscopic cytoreduction [46]. This observation is supported by the data published from the American Society of Peritoneal Surface Malignancies showing a median overall survival of 32.7 months in patients treated with complete macroscopic cytoreduction and MMCbased HIPEC vs. 31.4 months in patients after CC-0/1resection and oxaliplatin-based HIPEC [47]. Due to the small number of patients in the present series the survival difference between the two groups was not statistical significant $(\mathrm{p}=0.295)$ and therefore the relevance of this observation is limited. Moreover, there were a statistically not significant lower number of patients with appendiceal cancer and G1 differentiation as well as more patients with positive lymph node status in the IRI group. In a retrospective study Elias et al. reported a statistically significant improved overall 5-year survival rate of $63 \%$ for patients with peritoneal metastasis arising from appendiceal adenocarcinoma in comparison to colon $(29.7 \%)$ and rectal cancer $(37.9 \%)$. In the multivariate analysis positive lymph node status was an independent negative prognostic factor $(p=0.001)$ [48]. This observation has been confirmed by other published data [49,50]. Nevertheless, Jimenez et al. reported a median survival of 47 months and a 5-year survival rate of $41 \%$ after CRS and HIPEC in 125 patients with histologically proven peritoneal carcinomatosis (PMCA) arising from appendiceal cancer [51]. This survival data is comparable to the survival rates published for patients with colorectal peritoneal metastasis. However, in the present series the subgroup analysis of tumor origin, grading and lymph node status showed no significant differences.

\section{Conclusions}

In conclusion, our data show that both bidirectional HIPEC regimens may be used with comparable low mortality and acceptable morbidity in a specialized peritoneal carcinomatosis center. Published data and the positive trend regarding the overall 3-year survival rate in the present series support oxaliplatin-based HIPEC as the first choice treatment regimen. Nevertheless, in our opinion irinotecan-based HIPEC should still be considered as a promising alternative in patients with tumor progression or intolerable toxicity under chemotherapy with oxaliplatin. However, comparative prospective randomized trials are necessary to determine the best treatment regimen regarding morbidity, mortality and particularly long-term oncological outcome.

\section{Consent}

Written informed consent was obtained from the patient for inclusion into the database and publication of the data.

\section{Abbreviations}

5-FU: Fluorouracil; ASA: American Society of Anesthesiologists; CA19-9: Carbohydrate antigen 19-9; CC: Completeness of cytoreduction; CEA: Carcinoembryonic antigen; Cl: Confidence interval; CRC: Colorectal cancer; CRS: Cytoreductive surgery; CT: Computed tomography; CTCAE: Common Terminology Criteria for Adverse Events; DPAM: Disseminated peritoneal adenomucinosis; FA: Folinic acid; FOLFIRI: Folinic acid + fluorouracil + irinotecan; FOLFOX: Folinic acid + fluorouracil + oxaliplatin; FOLFOXIRI: Folinic acid + fluorouracil + irinotecan + oxaliplatin; HIPEC: Hyperthermic intraperitoneal chemotherapy; mCRC: Metastatic colorectal cancer; MMC: Mitomycin C;

OS: Overall survival; pcCRC: Peritoneal carcinomatosis of CRC; PCI: Peritoneal Cancer Index; PFS: Progression-free survival; PM: Peritoneal metastases; PMCA-I: Peritoneal mucinous carcinomatosis of intermediate features; QoL: Quality of life; RCT: Randomized controlled trial.

\section{Competing interests}

The authors declare that they have no competing interests.

\section{Authors' contributions}

GG drafted the manuscript. MG and MKS provided the survival data. SAL, PP and HJS revised the manuscript. All authors read and approved the final manuscript.

\section{Author details}

${ }^{1}$ Department of Surgery, University Hospital Regensburg, 93042 Regensburg, Germany. ${ }^{2}$ Tumor Center Regensburg e. V., University Regensburg,

Regensburg, Germany. ${ }^{3}$ Department of Surgery, Hospital of the Order of St. John of God, Regensburg, Germany.

Received: 23 April 2014 Accepted: 23 October 2014

Published: 4 November 2014 


\section{References}

1. Sugarbaker PH, Cunliffe WJ, Belliveau J, de Bruijn EA, Graves T, Mullins RE, Schlag P: Rationale for integrating early postoperative intraperitoneal chemotherapy into the surgical treatment of gastrointestinal cancer. Semin Oncol 1989, 16(4 Suppl 6):83-97.

2. Sugarbaker PH: New standard of care for appendiceal epithelial neoplasms and pseudomyxoma peritonei syndrome? Lancet Oncol 2006, 7(1):69-76.

3. Glehen O, Gilly FN, Boutitie F, Bereder JM, Quenet F, Sideris L, Mansvelt B, Lorimier G, Msika S, Elias D: Toward curative treatment of peritoneal carcinomatosis from nonovarian origin by cytoreductive surgery combined with perioperative intraperitoneal chemotherapy: A multi-institutional study of 1290 patients. Cancer 2010, 116(24):5608-5618.

4. Pilati P, Mocellin S, Rossi CR, Foletto M, Campana L, Nitti D, Lise M: Cytoreductive surgery combined with hyperthermic intraperitoneal intraoperative chemotherapy for peritoneal carcinomatosis arising from colon adenocarcinoma. Ann Surg Oncol 2003, 10(5):508-513.

5. Glehen O, Cotte E, Schreiber V, Sayag-Beaujard AC, Vignal J, Gilly FN: Intraperitoneal chemohyperthermia and attempted cytoreductive surgery in patients with peritoneal carcinomatosis of colorectal origin. $\mathrm{Br} J$ Surg 2004, 91(6):747-754.

6. Glehen O, Kwiatkowski F, Sugarbaker PH, Elias D, Levine EA, De Simone M, Barone R, Yonemura Y, Cavaliere F, Quenet F, Gutman M, Tentes AA, Lorimier G, Bernard JL, Bereder JM, Porcheron J, Gomez-Portilla A, Shen P, Deraco M, Rat P: Cytoreductive surgery combined with perioperative intraperitoneal chemotherapy for the management of peritoneal carcinomatosis from colorectal cancer: a multi-institutional study. J Clin Oncol 2004, 22(16):3284-3292.

7. Shen P, Hawksworth J, Lovato J, Loggie BW, Geisinger KR, Fleming RA, Levine EA: Cytoreductive surgery and intraperitoneal hyperthermic chemotherapy with mitomycin $\mathrm{C}$ for peritoneal carcinomatosis from nonappendiceal colorectal carcinoma. Ann Surg Oncol 2004, 11(2):178-186.

8. Verwaal VJ, Bruin S, Boot H, van Slooten G, van Tinteren H: 8-year follow-up of randomized trial: cytoreduction and hyperthermic intraperitoneal chemotherapy versus systemic chemotherapy in patients with peritoneal carcinomatosis of colorectal cancer. Ann Surg Oncol 2008, 15(9):2426-2432.

9. Verwaal VJ, van Ruth $\mathrm{S}$, de Bree E, van Sloothen GW, van Tinteren $\mathrm{H}$, Boot $\mathrm{H}$, Zoetmulder FA: Randomized trial of cytoreduction and hyperthermic intraperitoneal chemotherapy versus systemic chemotherapy and palliative surgery in patients with peritoneal carcinomatosis of colorectal cancer. J Clin Oncol 2003, 21(20):3737-3743.

10. Quenet F, Claus C, Roca L, Gauthey A, Essissen M, Ychou M, Rouanet P Saint-Aubert B: Complete cytoreductive surgery and hyperthermic intraperitoneal chemotherapy for peritoneal carcinomatosis from digestive tract cancer-New management with oxaliplatin plus irinotecan: A feasibility study in 37 patients. J Clin Oncol 2008, 26:Suppl. abstr 4084

11. Elias D, Lefevre JH, Chevalier J, Brouquet A, Marchal F, Classe JM, Ferron G, Guilloit JM, Meeus P, Goéré D, Bonastre J: Complete cytoreductive surgery plus intraperitoneal chemohyperthermia with oxaliplatin for peritoneal carcinomatosis of colorectal origin. J Clin Oncol 2009, 27(5):681-685.

12. Quenet F, Goere D, Mehta SS, Roca L, Dumont F, Hessissen M, Saint-Aubert B, Elias D: Results of two bi-institutional prospective studies using intraperitoneal oxaliplatin with or without irinotecan during HIPEC after cytoreductive surgery for colorectal carcinomatosis. Ann Surg 2011, 254(2):294-301.

13. Rougier P, Van Cutsem E, Bajetta E, Niederle N, Possinger K, Labianca R, Navarro M, Morant R, Bleiberg H, Wils J, Awad L, Herait P, Jacques C: Randomised trial of irinotecan versus fluorouracil by continuous infusion after fluorouracil failure in patients with metastatic colorectal cancer. Lancet 1998, 352(9138):1407-1412

14. Franko J, Shi Q, Goldman CD, Pockaj BA, Nelson GD, Goldberg RM, Pitot HC, Grothey A, Alberts SR, Sargent DJ: Treatment of colorectal peritoneal carcinomatosis with systemic chemotherapy: a pooled analysis of north central cancer treatment group phase III trials N9741 and N9841. J Clin Oncol 2012, 30(3):263-267.

15. Gonzalez-Moreno S, Gonzalez-Bayon LA, Ortega-Perez G: Hyperthermic intraperitoneal chemotherapy: Rationale and technique. World I Gastrointest Oncol 2010, 2(2):68-75.

16. Pox C, Aretz S, Bischoff SC, Graeven U, Hass M, Heussner P, Hohenberger W, Holstege A, Hubner J, Kolligs F, Kreis M, Lux P, Ockenga J, Porschen R, Post S, Rahner N, Reinacher-Schick A, Riemann JF, Sauer R, Sieg A, Scheppach W, Schmitt W, Schmoll HJ, Schulmann K, Tannapfel A, Schmiegel W: S3-guideline colorectal cancer version 1.0. Z Gastroenterol 2013, 51(8):753-854.
17. Glockzin G, Rochon J, Arnold D, Lang SA, Klebl F, Zeman F, Koller M, Schlitt HJ, Piso $P$ : A prospective multicenter phase II study evaluating multimodality treatment of patients with peritoneal carcinomatosis arising from appendiceal and colorectal cancer: the COMBATAC trial. BMC Cancer 2013, 13:67.

18. Elias D, Goere D, Blot F, Billard V, Pocard M, Kohneh-Shahri N, Raynard B: Optimization of hyperthermic intraperitoneal chemotherapy with oxaliplatin plus irinotecan at 43 degrees $C$ after compete cytoreductive surgery: mortality and morbidity in 106 consecutive patients. Ann Surg Oncol 2007, 14(6):1818-1824.

19. Cotte E, Passot G, Tod M, Bakrin N, Gilly FN, Steghens A, Mohamed F, Glehen $\mathrm{O}$ : Closed abdomen hyperthermic intraperitoneal chemotherapy with irinotecan and mitomycin C: a phase I study. Ann Surg Oncol 2011, 18(9):2599-2603.

20. Jacquet $\mathrm{P}$, Sugarbaker $\mathrm{PH}$ : Clinical research methodologies in diagnosis and staging of patients with peritoneal carcinomatosis. Cancer Treat Res 1996, 82:359-374.

21. Glehen O, Gilly FN: Quantitative prognostic indicators of peritoneal surface malignancy: carcinomatosis, sarcomatosis, and peritoneal mesothelioma. Surg Oncol Clin N Am 2003, 12(3):649-671.

22. Glockzin G, Ghali N, Lang SA, Agha A, Schlitt HJ, Piso P: Peritoneal carcinomatosis. Surgical treatment, including hyperthermic intraperitoneal chemotherapy. Chirurg 2007, 78(12):1100-1110.

23. Glockzin G, Schlitt HJ, Piso P: Peritoneal carcinomatosis: patients selection, perioperative complications and quality of life related to cytoreductive surgery and hyperthermic intraperitoneal chemotherapy. World I Surg Oncol 2009, 7(1):5.

24. Glehen O, Osinsky D, Cotte E, Kwiatkowski F, Freyer G, Isaac S, Trillet-Lenoir V, Sayag-Beaujard AC, Francois Y, Vignal J, Gilly FN: Intraperitoneal chemohyperthermia using a closed abdominal procedure and cytoreductive surgery for the treatment of peritoneal carcinomatosis: morbidity and mortality analysis of 216 consecutive procedures. Ann Surg Oncol 2003, 10(8):863-869.

25. Stephens AD, Alderman R, Chang D, Edwards GD, Esquivel J, Sebbag G, Steves MA, Sugarbaker PH: Morbidity and mortality analysis of 200 treatments with cytoreductive surgery and hyperthermic intraoperative intraperitoneal chemotherapy using the coliseum technique. Ann Surg Oncol 1999, 6(8):790-796.

26. Kusamura S, Younan R, Baratti D, Costanzo P, Favaro M, Gavazzi C, Deraco M: Cytoreductive surgery followed by intraperitoneal hyperthermic perfusion: analysis of morbidity and mortality in 209 peritoneal surface malignancies treated with closed abdomen technique. Cancer 2006, 106(5):1144-1153.

27. Franko J, Gusani NJ, Holtzman MP, Ahrendt SA, Jones HL, Zeh HJ 3rd, Bartlett DL: Multivisceral resection does Not affect morbidity and survival after cytoreductive surgery and chemoperfusion for carcinomatosis from colorectal cancer. Ann Surg Oncol 2008, 15(11):3065-3072.

28. Ferron G, Dattez S, Gladieff L, Delord JP, Pierre S, Lafont T, Lochon I, Chatelut E: Pharmacokinetics of heated intraperitoneal oxaliplatin. Cancer Chemother Pharmacol 2008, 62(4):679-683.

29. Mahteme H, Wallin I, Glimelius B, Pahlman L, Ehrsson H: Systemic exposure of the parent drug oxaliplatin during hyperthermic intraperitoneal perfusion. Eur J Clin Pharmacol 2008, 64(9):907-911.

30. Glockzin G, von Breitenbuch P, Schlitt HJ, Piso P: Treatment-related morbidity and toxicity of CRS and oxaliplatin-based HIPEC compared to a mitomycin and doxorubicin-based HIPEC protocol in patients with peritoneal carcinomatosis: a matched-pair analysis. J Surg Oncol 2013, 107(6):574-578.

31. Elias D, Bonnay M, Puizillou JM, Antoun $\mathrm{S}$, Demirdjian $\mathrm{S}$, El OA, Pignon JP, Drouard-Troalen $L$, Ouellet JF, Ducreux M: Heated intra-operative intraperitoneal oxaliplatin after complete resection of peritoneal carcinomatosis: pharmacokinetics and tissue distribution. Ann Oncol 2002, 13(2):267-272

32. Chua TC, Yan TD, Saxena A, Morris DL: Should the treatment of peritoneal carcinomatosis by cytoreductive surgery and hyperthermic intraperitoneal chemotherapy still be regarded as a highly morbid procedure?: a systematic review of morbidity and mortality. Ann Surg 2009, 249(6):900-907

33. Chalret du Rieu Q, White-Koning M, Picaud L, Lochon I, Marsili S, Gladieff L, Chatelut E, Ferron G: Population pharmacokinetics of peritoneal, plasma ultrafiltrated and protein-bound oxaliplatin concentrations in patients with disseminated peritoneal cancer after intraperitoneal hyperthermic chemoperfusion of oxaliplatin following cytoreductive surgery: correlation 
between oxaliplatin exposure and thrombocytopenia. Cancer Chemother Pharmacol 2014, 74(3):571-582.

34. Gusani NJ, Cho SW, Colovos C, Seo S, Franko J, Richard SD, Edwards RP, Brown CK, Holtzman MP, Zeh HJ, Bartlett DL: Aggressive surgical management of peritoneal carcinomatosis with low mortality in a high-volume tertiary cancer center. Ann Surg Oncol 2008, 15(3):754-763.

35. Jafari MD, Halabi WJ, Stamos MJ, Nguyen VQ, Carmichael JC, Mills SD, Pigazzi A: Surgical outcomes of hyperthermic intraperitoneal chemotherapy: analysis of the American College of Surgeons National surgical quality improvement program. JAMA Surg 2013, [Epub ahead of print].

36. Saltz LB, Cox JV, Blanke C, Rosen LS, Fehrenbacher L, Moore MJ, Maroun JA Ackland SP, Locker PK, Pirotta N, Elfring GL, Miller LL: Irinotecan plus fluorouracil and leucovorin for metastatic colorectal cancer. Irinotecan Study Group. N Engl J Med 2000, 343(13):905-914.

37. Goldberg RM, Sargent DJ, Morton RF, Fuchs CS, Ramanathan RK, Williamson SK, Findlay BP, Pitot HC, Alberts S: Randomized controlled trial of reduced-dose bolus fluorouracil plus leucovorin and irinotecan or infused fluorouracil plus leucovorin and oxaliplatin in patients with previously untreated metastatic colorectal cancer: a North American Intergroup Trial. J Clin Oncol 2006 24(21):3347-3353

38. Falcone A, Ricci S, Brunetti I, Pfanner E, Allegrini G, Barbara C, Crino L, Benedetti G, Evangelista W, Fanchini L, Cortesi E, Picone V, Vitello S, Chiara S, Granetto C, Porcile G, Fioretto L, Orlandini C, Andreuccetti M, Masi G, Gruppo Oncologico Nord Ovest: Phase III trial of infusional fluorouracil, leucovorin, oxaliplatin, and irinotecan (FOLFOXIRI) compared with infusional fluorouracil, leucovorin, and irinotecan (FOLFIRI) as first-line treatment for metastatic colorectal cancer: the Gruppo Oncologico Nord Ovest. J Clin Oncol 2007, 25(13):1670-1676.

39. de Gramont A, Figer A, Seymour M, Homerin M, Hmissi A, Cassidy J, Boni C, Cortes-Funes H, Cervantes A, Freyer G, Papamichael D, Le Bail N, Louvet C, Hendler D, de Braud F, Wilson C, Morvan F, Bonetti A: Leucovorin and fluorouracil with or without oxaliplatin as first-line treatment in advanced colorectal cancer. J Clin Oncol 2000, 18(16):2938-2947.

40. Giacchetti S, Perpoint B, Zidani R, Le Bail N, Faggiuolo R, Focan C, Chollet $P$, Llory JF, Letourneau Y, Coudert B, Bertheaut-Cvitkovic F, Larregain-Fournier D, Le Rol A, Walter S, Adam R, Misset JL, Lévi F: Phase III multicenter randomized trial of oxaliplatin added to chronomodulated fluorouracil-leucovorin as first-line treatment of metastatic colorectal cancer. J Clin Oncol 2000 18(1):136-147.

41. Lee DH, Oh SY, Lee YR, Huh SJ, Yoon HH, Kim SH, Lee S, Lee JH, Kim Y, Kim HJ, Lee S, Lee JH, Kim Y, Kim HJ, Kwon HC: A Phase II Study of Modified FOLFOX4 for Colorectal Cancer Patients with Peritoneal Carcinomatosis. Cancer Res Treat 2011, 43(4):225-230.

42. Tournigand $C$, Andre T, Achille E, Lledo G, Flesh M, Mery-Mignard D, Quinaux E, Couteau C, Buyse M, Ganem G, Landi B, Colin P, Louvet C, de Gramont A: FOLFIRI followed by FOLFOX6 or the reverse sequence in advanced colorectal cancer: a randomized GERCOR study. J Clin Oncol 2004, 22(2):229-237

43. Douillard JY, Cunningham D, Roth AD, Navarro M, James RD, Karasek $P$, Jandik P, Iveson T, Carmichael J, Alakl M, Gruia G, Awad L, Rougier P. Irinotecan combined with fluorouracil compared with fluorouracil alone as first-line treatment for metastatic colorectal cancer: a multicentre randomised trial. Lancet 2000, 355(9209):1041-1047.

44. Zani S, Papalezova K, Stinnett S, Tyler D, Hsu D, Blazer DG 3rd: Modest advances in survival for patients with colorectal-associated peritoneal carcinomatosis in the era of modern chemotherapy. J Surg Oncol 2013, 107(4):307-311.

45. Hompes D, D'Hoore A, Van Cutsem E, Fieuws S, Ceelen W, Peeters M, Van der Speeten K, Bertrand C, Legendre H, Kerger J: The treatment of peritoneal carcinomatosis of colorectal cancer with complete cytoreductive surgery and hyperthermic intraperitoneal peroperative chemotherapy (hipec) with oxaliplatin: a Belgian Multicentre Prospective Phase II Clinical Study. Ann Surg Oncol 2012, 19(7):2186-2194.

46. Hompes D, D'Hoore A, Wolthuis A, Fieuws S, Mirck B, Bruin S, Verwaal V: The use of Oxaliplatin or Mitomycin $C$ in HIPEC treatment for peritoneal carcinomatosis from colorectal cancer: A comparative study. J Surg Oncol 2014, 109(6):527-532.

47. Prada-Villaverde A, Esquivel J, Lowy AM, Markman M, Chua T, Pelz J, Baratti D, Baumgartner JM, Berri R, Bretcha-Boix P, Deraco M, Flores-Ayala G, Glehen O, Gomez-Portilla A, González-Moreno S, Goodman M, Halkia E, Kusamura S, Moller M, Passot G, Pocard M, Salti G, Sardi A, Senthil M, Spiliotis J, Torres-
Melero J, Turaga K, Trout R: The American Society of Peritoneal Surface Malignancies evaluation of HIPEC with Mitomycin C versus Oxaliplatin in 539 patients with colon cancer undergoing a complete cytoreductive surgery. J Surg Oncol 2014, [Epub ahead of print].

48. Elias D, Glehen O, Pocard M, Quenet F, Goere D, Arvieux C, Rat P, Gilly F: A comparative study of complete cytoreductive surgery plus intraperitoneal chemotherapy to treat peritoneal dissemination from colon, rectum, small bowel, and nonpseudomyxoma appendix. Ann Surg 2010, 251(5):896-901.

49. da Silva RG, Sugarbaker PH: Analysis of prognostic factors in seventy patients having a complete cytoreduction plus perioperative intraperitoneal chemotherapy for carcinomatosis from colorectal cancer. J Am Coll Surg 2006, 203(6):878-886.

50. Elias D, Gilly F, Boutitie F, Quenet F, Bereder JM, Mansvelt B, Lorimier G, Dube $P$, Glehen O: Peritoneal colorectal carcinomatosis treated with surgery and perioperative intraperitoneal chemotherapy: retrospective analysis of 523 patients from a multicentric French study. J Clin Oncol 2010, 28(1):63-68.

51. Jimenez W, Sardi A, Nieroda C, Sittig M, Milovanov V, Nunez M, Aydin N, Gushchin V: Predictive and prognostic survival factors in peritoneal carcinomatosis from appendiceal cancer after cytoreductive surgery with hyperthermic intraperitoneal chemotherapy. Ann Surg Oncol 2014, [Epub ahead of print].

doi:10.1186/1471-2407-14-807

Cite this article as: Glockzin et al: Oxaliplatin-based versus irinotecanbased hyperthermic intraperitoneal chemotherapy (HIPEC) in patients with peritoneal metastasis from appendiceal and colorectal cancer: a retrospective analysis. BMC Cancer 2014 14:807.

\section{Submit your next manuscript to BioMed Central and take full advantage of:}

- Convenient online submission

- Thorough peer review

- No space constraints or color figure charges

- Immediate publication on acceptance

- Inclusion in PubMed, CAS, Scopus and Google Scholar

- Research which is freely available for redistribution 